

Head and Neck Infection

\title{
Treatment of Purulent Wounds in Patients with Phlegmons of the Maxillofacial and Neck Areas
}

\author{
Oleksii 0. Tymofieieva, ${ }^{a}$, Olexander V. Umirov ${ }^{b}$, Anton 0. Myroshnyk, \& Sergii I. Dubichenko ${ }^{d}$
}

\section{A B S T R A C T}

\section{Purpose}

To determine the effectiveness of the use of the antiseptic solution "Octenisept" in complex for the treatment of purulent wounds in patients with phlegmons of the maxillofacial and neck areas.

\section{Methods}

A clinical examination of 38 patients with phlegmons of the maxillofacial area and neck was conducted.

\section{Intervention}

Radical excision of an upper lip mass with microscopically negative margins and immediate reconstruction using Abbe flap followed by delayed flap separation.

\section{Results}

On the basis of the conducted examinations of patients with phlegmons of the maxillofacial area and neck it was objectively proved that the antiseptic solution "Octenisept" used for the local treatment of purulent wounds has a pronounced antiseptic effect, which is much higher than that of traditional antiseptic agents (chlorhexidine).

\section{Conclusions}

In patients with phlegmons of the maxillofacial area and neck the antiseptic solution "Octenisept" may be recommended for the local treatment of purulent wounds in order to prevent the development of severe inflammatory complications.

\footnotetext{
a ScD, Professor. Head, Department of Maxillofacial Surgery, Stomatology Institute, Shupyk National Medical Academy of Postgraduate Education, Kyiv, Ukraine.

${ }^{b}$ Assistant Professor, Department of Oral and Maxillofacial Surgery, Private Higher Educational Establishment “Kyiv Medical University”, Kyiv, Ukraine.

${ }^{c}$ Assistant Professor, Department of Oral and Maxillofacial Surgery, Private Higher Educational Establishment “Kyiv Medical University”, Kyiv, Ukraine.

${ }^{d}$ Assistant Professor, Department of Oral and Maxillofacial Surgery, Private Higher Educational Establishment “Kyiv Medical University”, Kyiv, Ukraine.

* Corresponding author. Department of Maxillofacial Surgery, NMAPE,
}



The article was simultaneously published in Journal of Diagnostics and Treatment of Oral and Maxillofacial Pathology and Modern Dentistry

http://dx.doi.org/10.23999/j.dtomp.2019.6.2.

(C) 2019 OMF Publishing, LLC. This is an open access article under the CC BY license (http://creativecommons.org/licenses/by-nc/4.0/). 
The problem of purulent infections affecting the maxillofacial region is now extremely important. It has repeatedly been the subject of discussion at congresses, symposia, conferences and other forums both in this country and abroad. Numerous studies of native and foreign authors are devoted to its development.

More than forty years ago (ie, during the period of mass use of antibiotics) even small doses of these drugs prevented the development of purulent complications, including sepsis and mediastinitis. The successes achieved in the treatment of purulent infections were so great that many doctors considered the problem of the prevention and treatment of surgical infection solved. This led to the fact that they began to neglect the established principles and methods of antibiotics. In surgical hospitals the gradual elimination of departments for the treatment of purulent infections has started. The widespread use of antibiotics led to changes in species composition and properties of the pyogenic microbial flora, and this, in turn, reduces the effectiveness of antibiotic therapy. In recent years, an increase in the frequency of purulent diseases of the maxillofacial area as well as the number of postoperative complications and the transition of acute purulent-inflammatory processes to chronic ones has been noted. The number of deaths due to purulent diseases and their complications has increased. All this attracted the attention of doctors to the problem of purulent infection ones again. ${ }^{1-6}$

Despite the use of antibiotics, the number of purulent complications is steadily increasing and now it has reached the level of the 40-50 of the last century.

The reasons for the increase in the number of patients with inflammatory diseases of the soft tissues of the maxillofacial area and neck are the following:

- Late appeal for medical care, which is associated with insufficiently conducting sanitary and educational work among the population.

- Medical errors made at the prehospital stage of treatment, and often self-medication of patients.

- Established stereotype in the appointment of drug therapy; late diagnosis of diseases and developed complications, and, consequently, incorrect treatment tactics.
- Changes in the species composition of pathogens and reduced reactivity of the patient.

Purulent-inflammatory diseases of soft tissues are one of the most common types of pathology in the clinic of maxillofacial surgery. In recent years, the number of patients with these diseases has increased significantly, the severity of the process has worsened, which often leads to such severe and formidable complications, such as mediastinitis, sepsis, thrombophlebitis of the face and sinuses of the brain.

From January 1969 to December 2018, the clinic of maxillofacial surgery of Shupyk National Medical Academy of Postgraduate Education marked an increase in the number of patients with inflammatory diseases of the face and neck from 53.5 to 75.9 percent. The prevalence of highly pathogenic and antibiotic-resistant microorganisms leads to the occurrence of severe forms of inflammatory diseases of the maxillofacial region, accompanied by severe intoxication, impaired immunological status of the body, resulting in reduced levels of humoral and cellular immunity factors, which contributes to the development of severe complications (sepsis, mediastinitis, etc.). In recent years, the number of deaths of patients with these complications has increased and amounted to $0.13-0.30$ percent. ${ }^{4,6}$

In the absolute majority of cases (90-96 percent), the etiological factor of inflammatory diseases of the maxillofacial region is an odontogenic infection. In only $4-10 \%$ of cases, microorganisms can be brought into the soft tissues of the face and neck from non-odontogenic foci (carbuncles, boils, inflamed palatine tonsils, infected wounds, etc.), lymphogenous, contact and dermatogenic pathways.

Through the carious cavity in the tooth, microorganisms enter the pulp tissue. If these bacteria are devoid of pathogenic properties, then their first contact with the pulp tissues may not be accompanied by the development of a pronounced inflammatory reaction. However, the penetration of the products of vital activity of microorganisms through the system of lymphatic vessels into the regional lymph nodes, followed by their fixation by immunocompetent cells, already at this phase of the development of the pathological process can cause the production of antibodies and sensitization of the 
organism. As a result of the subsequent receipt of the same non-pathogenic microbes into the pulp tissue of a sensitized organism, an allergic inflammation may develop. Sometimes the penetration of microorganisms into the tissue of the tooth pulp is preceded by sensitization of the organism to the identical microflora of some other source of infection. In this case, the first introduction of microbes into the pulp of the tooth may be accompanied by the development of allergic inflammation.

The peculiarity of odontogenic foci of inflammation is that the defects of the hard tissues of the tooth, which are the entrance gates of the infection, are not naturally compensated. This causes a constant additional infection of the tissues of the maxillofacial area and contributes to the formation of foci of chronic infection. A kind of dynamic equilibrium is established between such a focus of infection and the patient's body. It can be impaired as a result of the immunological reactivity of the patient, an increase in the virulence of the infectious agent, or if the connective tissue capsule surrounding the infectious focus is damaged.

The currently used methods of treatment of various forms of complicated caries - pulpitis, periodontitis - cannot be considered perfect. The usefulness of tooth canal filling is 60-70 percent. Chronic foci of inflammation in the therapeutic treatment of periodontitis do not disappear immediately after the completion of canal filling in the tooth, even if this treatment is complete. In 22 percent of patients, foci of chronic odontogenic inflammation disappear in 4-8 months, and in $68 \%$ - only in 1-2 years or later. ${ }^{1-7}$

Violation of certain methods and terms of treatment of patients with periodontitis, pulpitis leads to the fact that the foci of open infection become closed, undrained and become one of the main sources causing sensitization of the organism to bacteria, toxins and decomposition products of damaged tissues.

The causative agents of purulent diseases of the soft tissues of the maxillofacial area are staphylococci, streptococci, intestinal and pseudomonas bacilli, proteus, anaerobes and other microorganisms, as well as their associations. ${ }^{8-17}$ Purulent-inflammatory processes are polymicrobial in nature and result from the action of aerobic, facultative and anaerobic bacteria. Improvement of microbiological research methods has provided convincing evidence that anaerobic bacteria can be the causative agents of odontogenic infection. At the same time, bacteroides, fusobacteria, peptococci, peptostreptococci, veylonella and other anaerobic microorganisms occupy a significant place among them. The pathological process caused by these pathogens is characterized by different localization and variety of clinical manifestations, depending on the species composition of the pathogens. In addition, the resistance of bacteroides, especially the type of fragilis, to a wide range of antibiotics creates difficulties in treating patients. ${ }^{1-5}$

Recent studies have noted that the main causative agents of acute odontogenic infection include not only staphylococcus, but also various representatives of gram-negative microflora: Proteus, E. coli, Klebsiella, etc. More and more often there are reports that the purulent contents of the lesions of odontogenic inflammation are "sterile". The reason for this conclusion is that in this case the development of the inflammatory process occurs under the influence of anaerobic microorganisms, which cannot be detected on ordinary media. Therefore, to identify anaerobes a special transport medium is used.

In the clinic of maxillofacial surgery, abscesses and cellulitis of the maxillofacial area and neck, in terms of frequency of their occurrence, occupy one of the first places. ${ }^{18-30}$ In recent years, the number of patients with this pathology has increased significantly, the course y of the process has worsened, which often leads to such severe complications as mediastinitis, sepsis, facial vein thrombosis of the face and brain sinuses. Thus, the relevance of this research topic does not cause doubts.

Considering the aforementioned polymicrobial nature of the purulent focus for the local treatment of purulent wounds, our attention was drawn to the water antiseptic - the drug Octenisept (Schülke and Mayr GmbH, Norderstedt, Germany). ${ }^{7}$ This drug has a very wide range of antimicrobial action. The action is carried out due to the hydrophobic interaction of octenidine dihydrochloride and phenoxyethanol with the cytoplasmic membranes of pathogenic microorganisms. $100 \mathrm{~g}$ of the solution for external use contains $0.1 \mathrm{~g}$ of octenidine dihydrochloride and 0.2 $\mathrm{g}$ of phenoxyethanol. The mechanism of action of the drug is based on the ability of its active components to destroy the cell membranes of susceptible microorganisms. Gram-positive and gram-negative 
microorganisms are sensitive to the action of the drug, including: Mycobacterium tuberculosis, Streptococcus spp. (including Streptococcus pneumoniae), Staphylococcus spp. (including Staphylococcus aureus), Enterococcus spp., Neisseria gonorrhoeae, Neisseria meningitides, Escherichia coli, Shigella spp., Proteus mirabilis, Pseudomonas aeruginosa, Corynebacterium diphtheriae, Gardnerella vaginal. In addition, mushrooms are sensitive to the action of the drug, including Ascomycota, Trichophyton spp. and Microsporum spp., Candida albicans. The drug is active against viruses, including herpes simplex virus, hepatitis B, C and D virus, human immunodeficiency virus. Sensitivity to the Octenisept preparation was also observed in Chlamydia trachomatis, Trichomonas vaginalis, Mycoplasma spp. and Ureaplasma spp. The drug exhibits bactericidal, fungicidal and virostatic activity against strains resistant to the action of other chemotherapeutic drugs. The drug is low toxic, not absorbed into the systemic circulation, including through the wound surface. When using the drug, acceleration of healing processes is noted due to some immunostimulating action of the drug. After external use, the effect of the drug develops within 30 seconds and persists for a long time.

Patients with purulent wounds are treated on areas of the skin with undiluted drug, which is applied to a cotton swab, gauze bandage or sprayed with a special nozzle. In order to prevent and treat topical inflammation of the oral cavity and nasopharynx, Octenisept should be diluted with purified water or $0.9 \%$ sodium chloride solution in a $1: 2$ or $1: 3$ ratio, and when washing the cavities (maxillary or frontal sinuses) or processing nasal passages - in the ratio of 1: 6 (order No. 273 of 03/28/2016, registration certificate No. UA/4056/01/01). Octenisept is not compatible with iodine-containing drugs (antiseptics). Frequency of use of Octenisept - 2-3 times a day, if necessary - up to 6 times a day.

The purpose of this study is to determine the effectiveness of the Octenisept for the local treatment of patients with abscesses and phlegmon of the maxillofacial and neck areas.

\section{MATERIALS \& METHODS}

To solve the problem, we examined 38 patients with abscesses and phlegmons of the maxillofacial area and neck, aged 17 to 67 years (Fig 1). We divided all 38 patients with phlegmon into two groups of observation: Group I (main) - 20 patients who, in the complex of standard medical treatment for local impact on the purulent wound, used the drug in the purulent necrotic phase of the wound process (after opening the cellulitis). Group II (control) - 18 patients whom was given a 0.1 percent sterile chlorhexidine bigluconate solution to wash purulent wounds and applied in the complex of standard treatment for local impact on a purulent wound, in the purulentnecrotic phase of the wound process (after opening the phlegmon) and antiseptic dressings.

All patients underwent surgical treatment (removal of the causal tooth and dissection of phlegmon) followed by drug therapy (including antibacterial, detoxification, general strengthening and symptomatic treatment, immunotherapy).

The difference in treatment between the examined groups was only in the fact that patients of the group I (main group) for the local treatment of purulent wounds used the drug Octenisept, and patients of the group II (control group) had a $0.1 \%$ chlorhexidine solution.

During hospitalization and in the dynamics of treatment of patients, we conducted a microbiological (identification of the identified microflora and the establishment of its antibiotic sensitivity) and general clinical examination. The latter included: examination, palpation, medical history taking, radiography of the jaws and other methods. The presence of microflora in the purulent wound was determined in the course of the treatment. We conducted a comparative analysis of the effect of the drug "Octenisept" and chlorhexidine on local clinical symptoms: the edges of postoperative purulent wounds (severity of hyperemia and their infiltration), its walls (depending on the severity of fibrin plaque, the presence of areas of necrosis, purulent or serous their impregnation), discharge from the purulent wound, the timing of granulation, changes in the area of purulent wounds. We also studied the severity of inflammatory infiltration of perimaxillary soft tissues.

Clinical symptoms and the obtained laboratory data were processed by a variation-statistical method using a personal computer. The reliability of the survey results was calculated according to Student's criteria. Differences were considered significant at $\mathrm{p}$ $<0.05$. 




FIGURE 1. Appearance of patients with odontogenic phlegmons (A-C) of various localizations. (Fig 1 continued on next page.) 


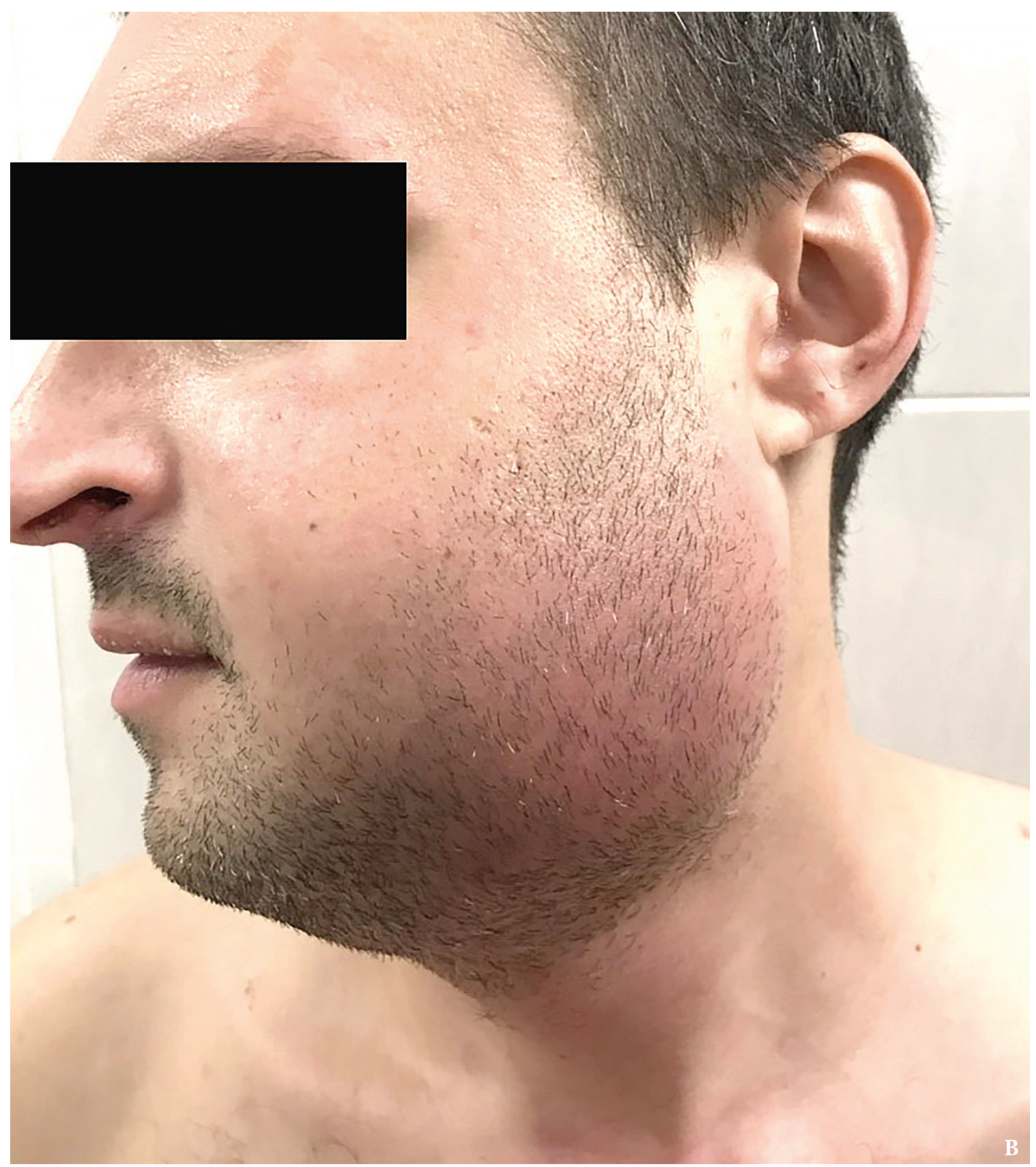

FIGURE 1 (cont'd). Appearance of patients with odontogenic phlegmons of various localizations (A-C). (Fig 1 continued on next page.) 


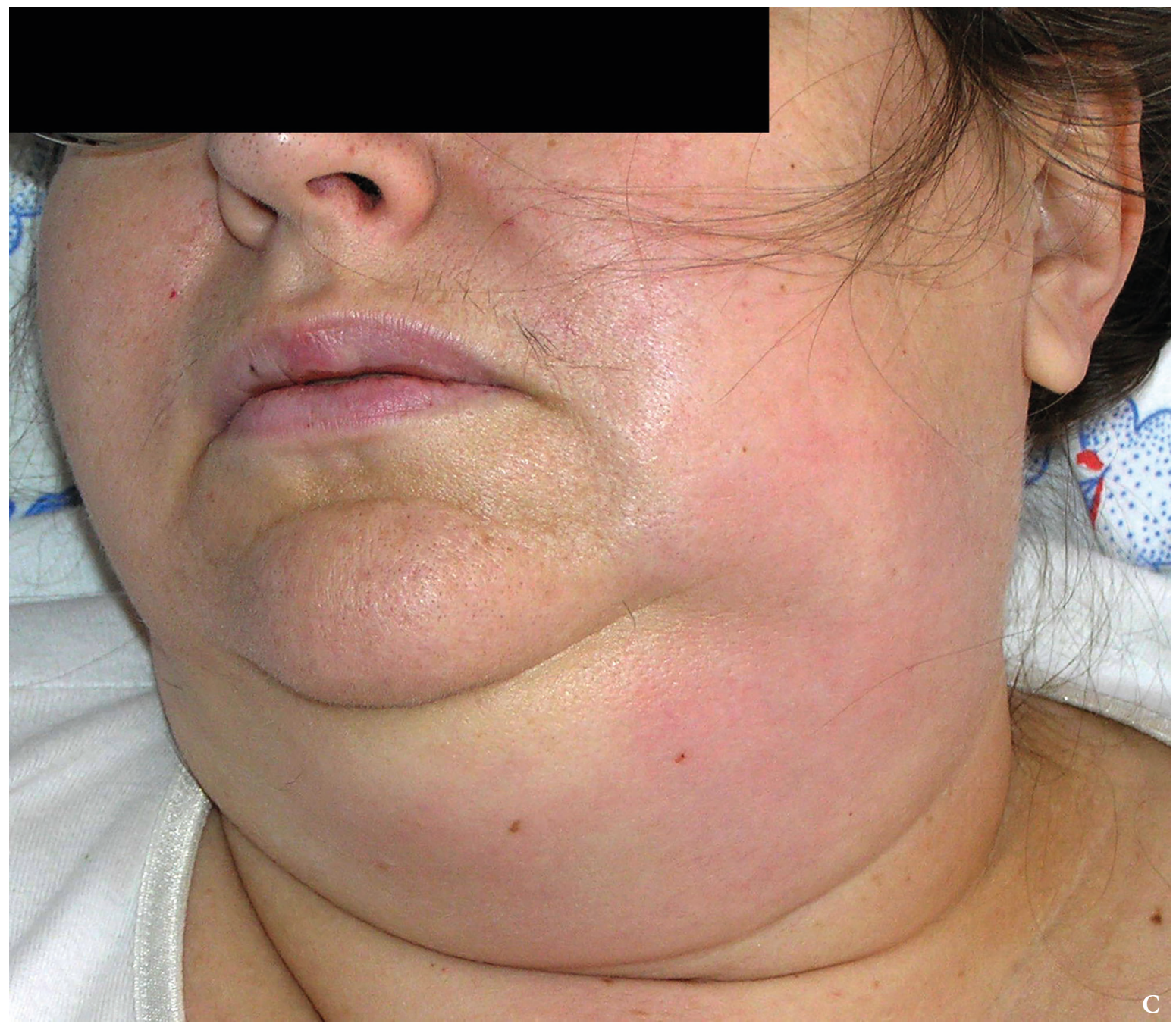

FIGURE 1 (cont'd). Appearance of patients with odontogenic phlegmons of various localizations (A-C). 


\section{RESULTS \& DISCUSSION}

Based on microbiological studies, it was established that not only aerobes (in 78.8\%), but also anaerobes $(21.2 \%)$ were found in patients with odontogenic phlegmon in purulent foci. Microorganisms were both in monoculture -67.5 percent (aerobes -56.7 percent, anaerobes -8.8 percent), and in associations - $32.5 \%$ (only aerobes - $20 \%$, only anaerobes 2.5 percent, aerobes and anaerobes - 10 percent). Aerobes were represented by Staphylococcus aureus and S. epidermidis, Escherichia coli, hemolytic streptococcus, enterococci, Proteus and diplococcus. Gram-negative bacteria (bacteroids, veylonones) and gram-negative bacteria (peptostreptococci, eubacteria) were found among anaerobes. In monoculture, S. aureus and S. epidermidis, veylonella, peptostreptococci and eubacteria were sown more often.

Thus, when spilled purulent processes of soft tissues that were located in the same anatomical region the monocultures of aerobic microorganisms were detected, and in patients with cellulitis which occupied two or more anatomical areas (floor of mouth, half of the face) - anaerobic monocultures, only anaerobic associations, associations of different types of aerobes, as well as anaerobic and aerobic microbes.

In patients with diffuse purulent-inflammatory processes in the soft tissues of monoculture, staphylococci were sensitive to aminoglycoside preparations and, to a lesser extent, to semisynthetic penicillins and anti-staphylococcal antibiotics of the reserve. In associations with aerobes, the antibiotic sensitivity of staphylococci was significantly reduced, and with anaerobes, staphylococci were resistant to all antibiotics except aminoglycosides and cephalosporins. Hemolytic streptococci were sensitive to most of the antibiotics studied, which did not depend on their associative connections. Gramnegative aerobic microorganisms (intestinal and Pseudomonas aeruginosa, enterococcus, protei) and their associations, which were sensitive to aminoglycoside and cephalosporin preparations, rarely to other antibiotics, showed the greatest resistance to antibiotics.

We determined the frequency of inoculation of pathogenic microorganisms from the purulent focus in patients with phlegmon of the maxillofacial area and neck in the dynamics of the treatment carried out in the main and control groups (Fig 2).

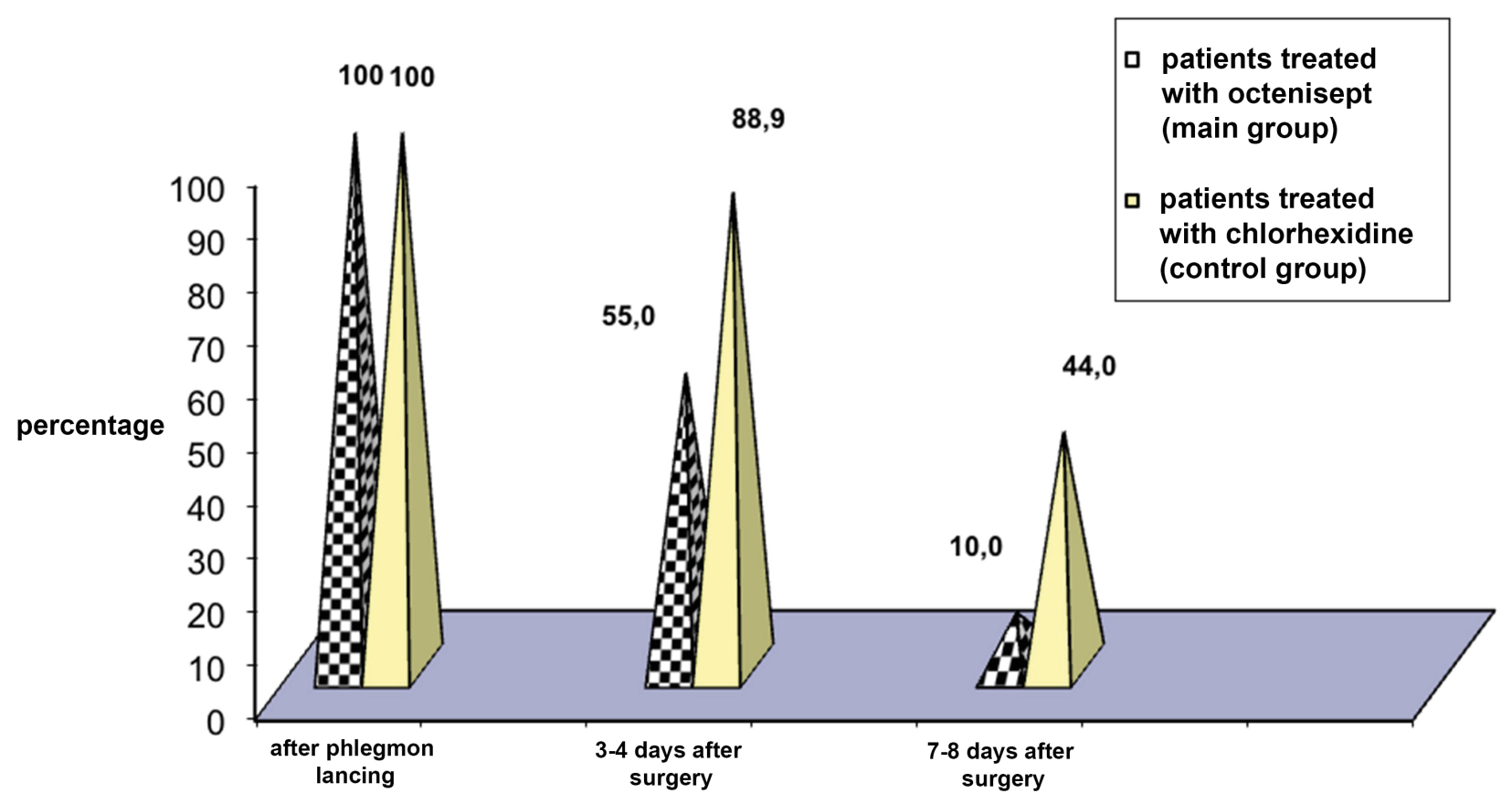

FIGURE 2. The frequency of inoculation of pathogenic microorganisms from the purulent focus in patients with phlegmon of the maxillofacial area and neck. 
Immediately after opening the cellulitis from the purulent focus, in the main and control observation groups, the microorganisms were seeded in $100 \%$. For 3-4 days of the local treatment with Octenisept (main group), the microorganisms from the purulent focus were sown in 11 patients (55\%), and in the treatment with chlorhexidine (control group) - in 16 patients (88.9\%). On the $7-8$ th day of the treatment, in the main observation group, microorganisms from the purulent focus were sown in 2 subjects (10 percent), and in the control group - in 8 patients (44.4\%).

Changes in the severity of hyperemia of the purulent wound edges were studied in patients with phlegmon of the maxillofacial area and neck in the dynamics of the treatment carried out (Fig 3). It was established that on the next day after the opening of the phlegmon, a pronounced hyperemia of the festering wound edges was noted in 100 percent of cases both in the main observation group and in the control group. On the 3-4th day of the local treatment with the drug "Octenisept" (main group), severe hyperemia of the festering wound edges was observed in 9 patients (45\%), and moderate - in 11 patients (55\%). For 3-4 days of treatment with chlorhexidine (control group), severe hyperemia of the purulent wound edges occurred in 14 patients (77.8 percent), and moderate - in 4 patients ( 22.2 percent). At 7-8 days of treatment with the drug "Octenisept", moderate hyperemia was observed in 6 patients (30 percent), while the rest had no wound edges in the hyperemia (70 percent). On the 7-8th day of the local treatment with chlorhexidine, moderate hyperemia of the purulent wound edges was found in 8 subjects (44.4 percent), and in the rest of the patients there was no hyperemia (55.6\%).



FIGURE 3. Changes in the severity of hyperemia of the purulent wound edges in patients with phlegmon of the maxillofacial area and neck in the dynamics of treatment. 
Changes in the severity of inflammatory infiltration of the edges of a purulent wound in patients with phlegmon of the maxillofacial area and neck were determined in the dynamics of the treatment (Fig 4). It was established that the next day after the opening of the phlegmon, a pronounced inflammatory infiltration of the edges of the purulent wounds was observed in $100 \%$ of cases both in the main observation group and in the control group. For 3-4 days of the local treatment with the drug "Octenisept" (main group), severe inflammatory infiltration of the festering wound edges was observed in 10 patients (50 percent) and moderate in 10 patients (50.0\%). For 3-4 days of treatment with chlorhexidine (control group), severe inflammatory infiltration of the edges of the purulent wounds occurred in 16 patients (88.9\%), and moderate - in 2 patients (11.1\%). At 7-8 days of treatment with the drug "Octenisept", moderate inflammatory infiltration was observed in 4 patients (20 percent), and in the rest - inflammatory infiltration of the wound edges was insignificant (80.0\%). On the 7-8th day of the local treatment with chlorhexidine, moderate inflammatory infiltration of the edges of the purulent wounds was found in 9 patients (50 percent) and in the rest inflammatory infiltration of the wound edges was insignificant (50 percent).

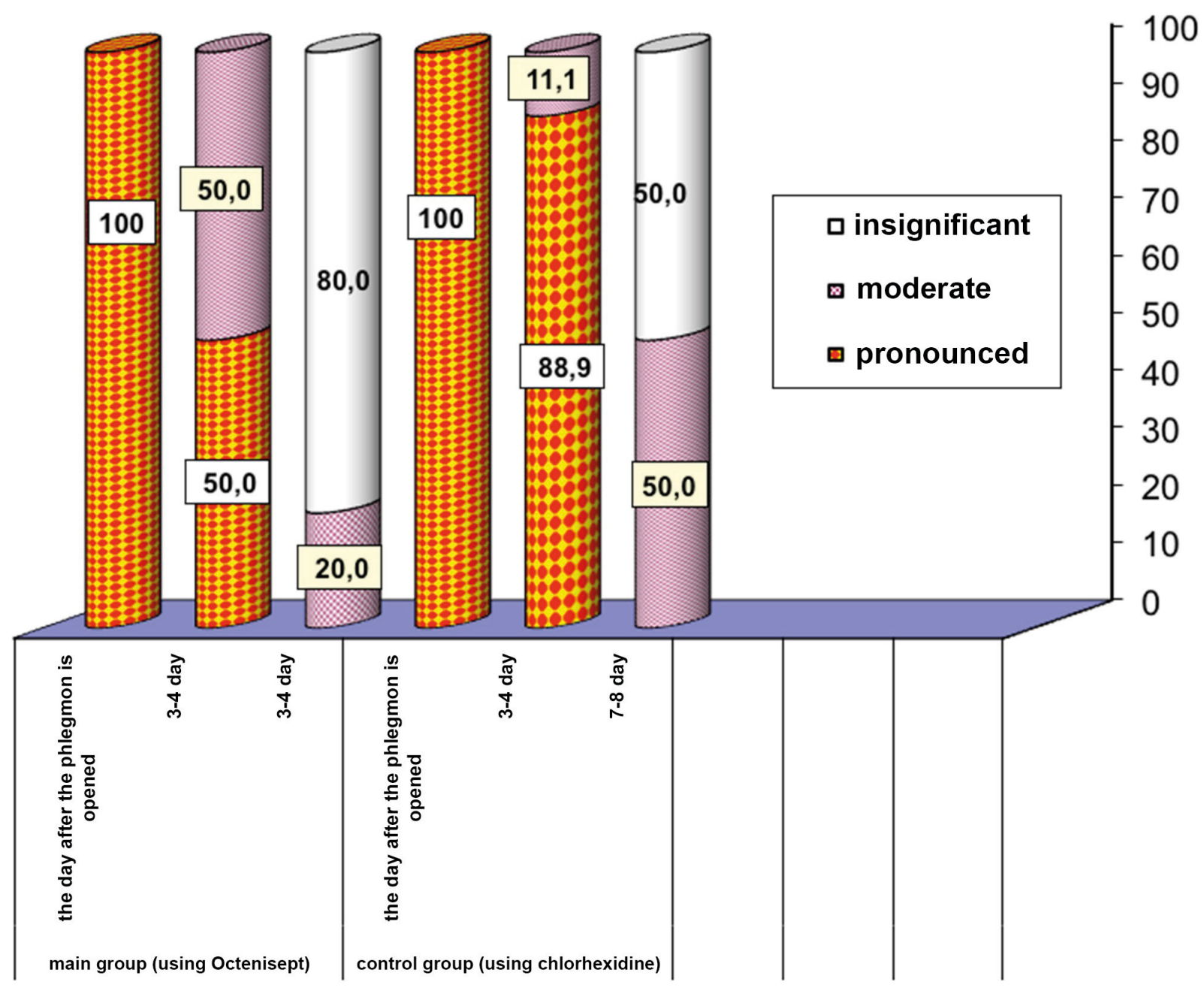

FIGURE 4. Dynamics of treatment: Changes in the severity of inflammatory infiltration of the edges of purulent wounds in patients with phlegmon of the maxillofacial and neck areas. 
Changes in the severity of fibrin plaque on the walls of purulent wounds in patients with phlegmon of the maxillofacial and neck areas in the dynamics of the treatment carried out (Fig 5) were revealed. It was established that the next day after the opening of the phlegmon, a pronounced fibrin deposit of the walls of a purulent wound was noted in $100 \%$ of cases in both groups of observations. On the 3-4th day of the local treatment with the drug "Octenisept" (main group), a pronounced fibrin deposit of the purulent wound walls was observed in 12 patients (60\%) and moderate - in 8 patients (40 percent). For 3-4 days of treatment with chlorhexidine (control group), a pronounced fibrin deposit of purulent wound walls occurred in 14 patients $(77.8 \%)$, and moderate - in 4 patients (22.2\%). At 7-8 days of treatment with the drug "Octenisept" moderate fibrin plaque of the walls of purulent wounds was observed in 4 patients (20.0\%), and in the rest (80\%) - fibrin walls of the purulent wounds was insignificant. On the 7-8th day of the local treatment with chlorhexidine, moderate plaque of the fibrin of the purulent wound walls was found in 9 patients (50\%), and in the rest $(50 \%)$ - the fibrin of the purulent wound walls was insignificant.

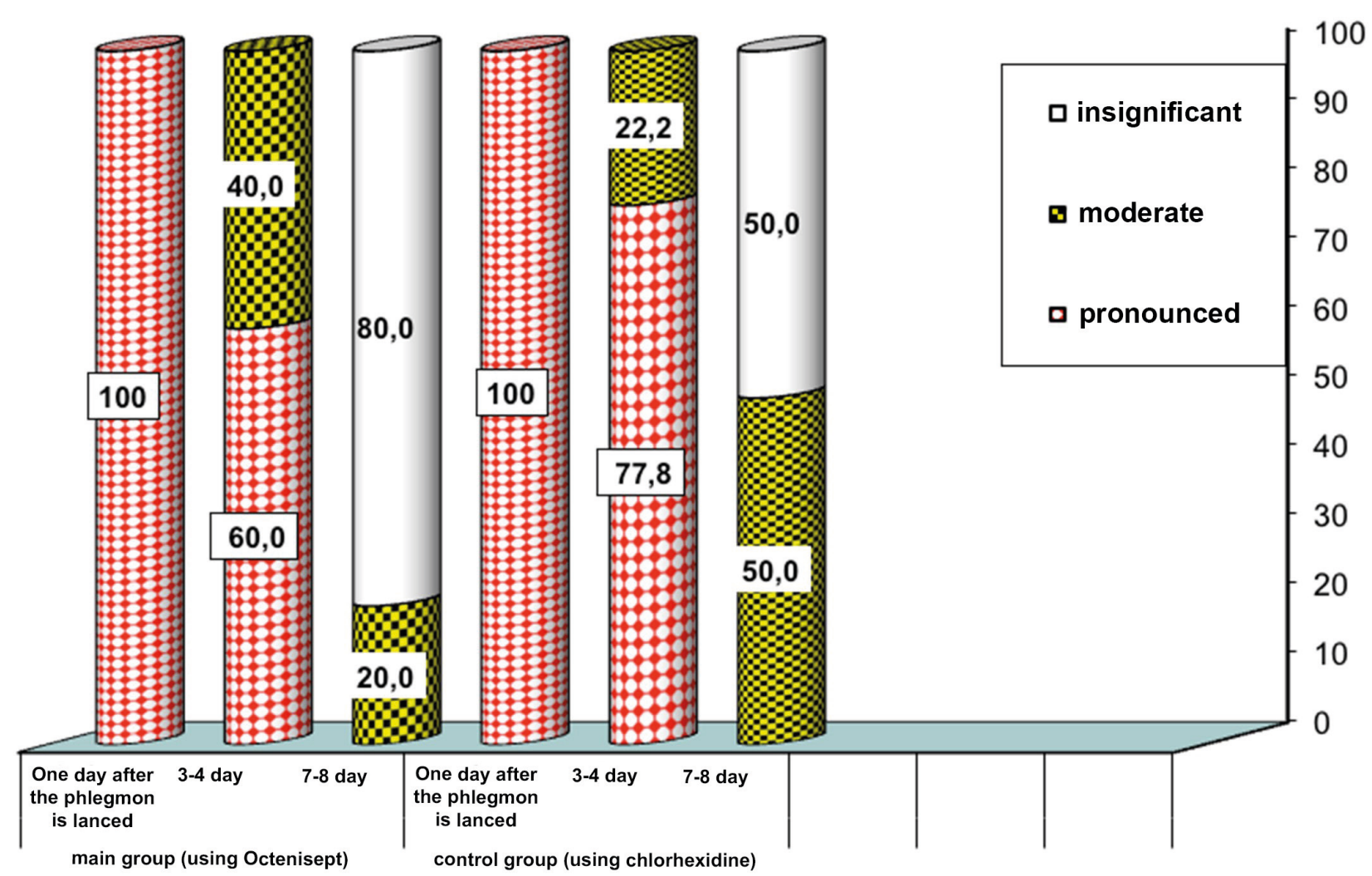

FIGURE 5. Dynamics of the treatment: Changes in the severity of fibrin plaque on the walls of purulent wounds in patients with phlegmon of the maxillofacial and neck areas.

The presence of purulent-serous impregnation of the walls of the purulent wound in patients with phlegmon of the maxillofacial area and neck in the dynamics of the treatment carried out was clarified (Fig 6). It was established that the day after the opening of the cellulitis purulent soaking of the walls of the purulent wounds was observed in
$100 \%$ of cases both in the main observation group and in the control group. For 3-4 days of the local treatment with Octenisept (main group), purulent soaking of the walls of the purulent wounds was observed in 9 patients (45.0\%), and serous - in 11 patients (55\%). On the 3-4th day of the treatment with chlorhexidine (control group), purulent 
soaking of the walls of the purulent wounds was found in 14 patients $(77.8 \%)$, and serous - in 4 patients $(22.2 \%)$. On the 7-8 day of treatment with Octenisept, serous soaking of the walls of the purulent wounds was observed in 6 patients (30\%), while the rest did not have the soaking of the walls of the purulent wounds (70\%). On the 7-8th day of the local treatment with chlorhexidine, serous soaking of the walls of the purulent wounds was found in 8 subjects $(44.4 \%)$, while the remaining ones did not have the soaking of the walls of the purulent wounds (55.6\%).

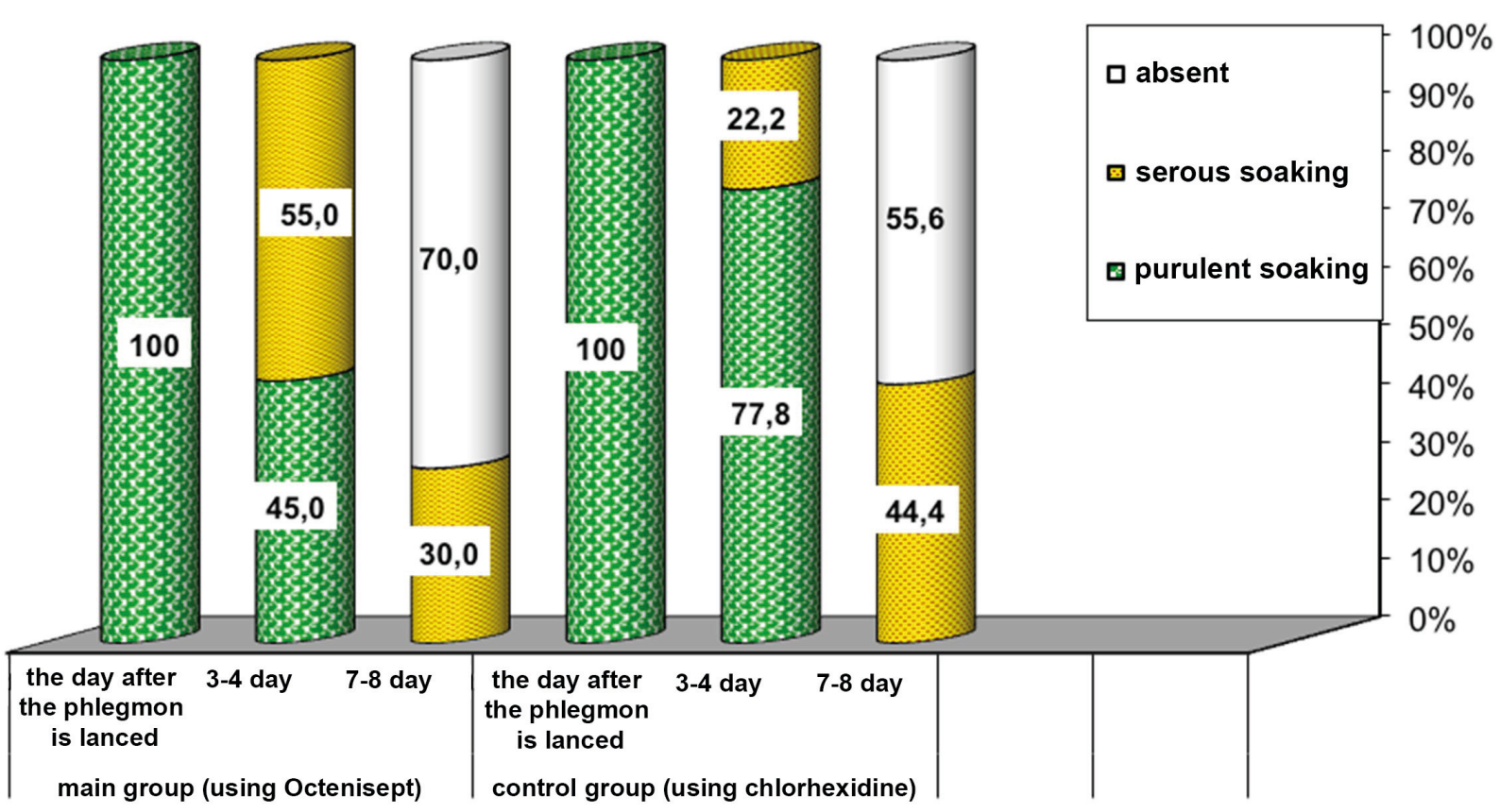

FIGURE 6. The presence of purulent-serous soaking of the walls of a purulent wound in patients with phlegmon of the maxillofacial area and neck in the dynamics of the treatment.

The presence of a discharge from a purulent wound was determined in patients with phlegmon of the maxillofacial area and neck in the dynamics of the treatment carried out (Fig 7). It was established that the day after the opening of the phlegmon, the purulent discharge from the postoperative wound was noted in 100 percent of cases both in the main observation group and in the control group. On the 3-4th day of the local treatment with the drug "Octenisept" (main group), purulent discharge from the wound was observed in 8 patients (40.0\%), and serous - in 12 patients (60\%). For 3-4 days of treatment with chlorhexidine (control group), purulent discharge from the postoperative wound occurred in 12 patients (66.7\%), and serous - in 6 patients (33.3\%). At 7-8 days of treatment with the drug "Octenisept" serous discharge from the postoperative wound was observed in 4 patients $(20$ percent), and in the rest - there was no discharge from the postoperative wound (80\%). On the 7-8th day of the local treatment with chlorhexidine, the serous discharge from the postoperative purulent wound was found in 8 patients (44.4\%), and in the rest - the discharge from the postoperative purulent wound was absent (55.6\%).

The time of appearance of granulations in the postoperative purulent wound in patients with maxillofacial phlegmon of the maxillofacial area and neck was determined in the dynamics of the treatment carried out (Fig 8). On the 3-4th day of the local treatment with the drug "Octenisept" (main group), the appearance of the first bright red granulations in the postoperative purulent wound in patients with phlegmon was observed in 3 patients (15\%), and during the same periods of treatment with chlorhexidine (control group) 


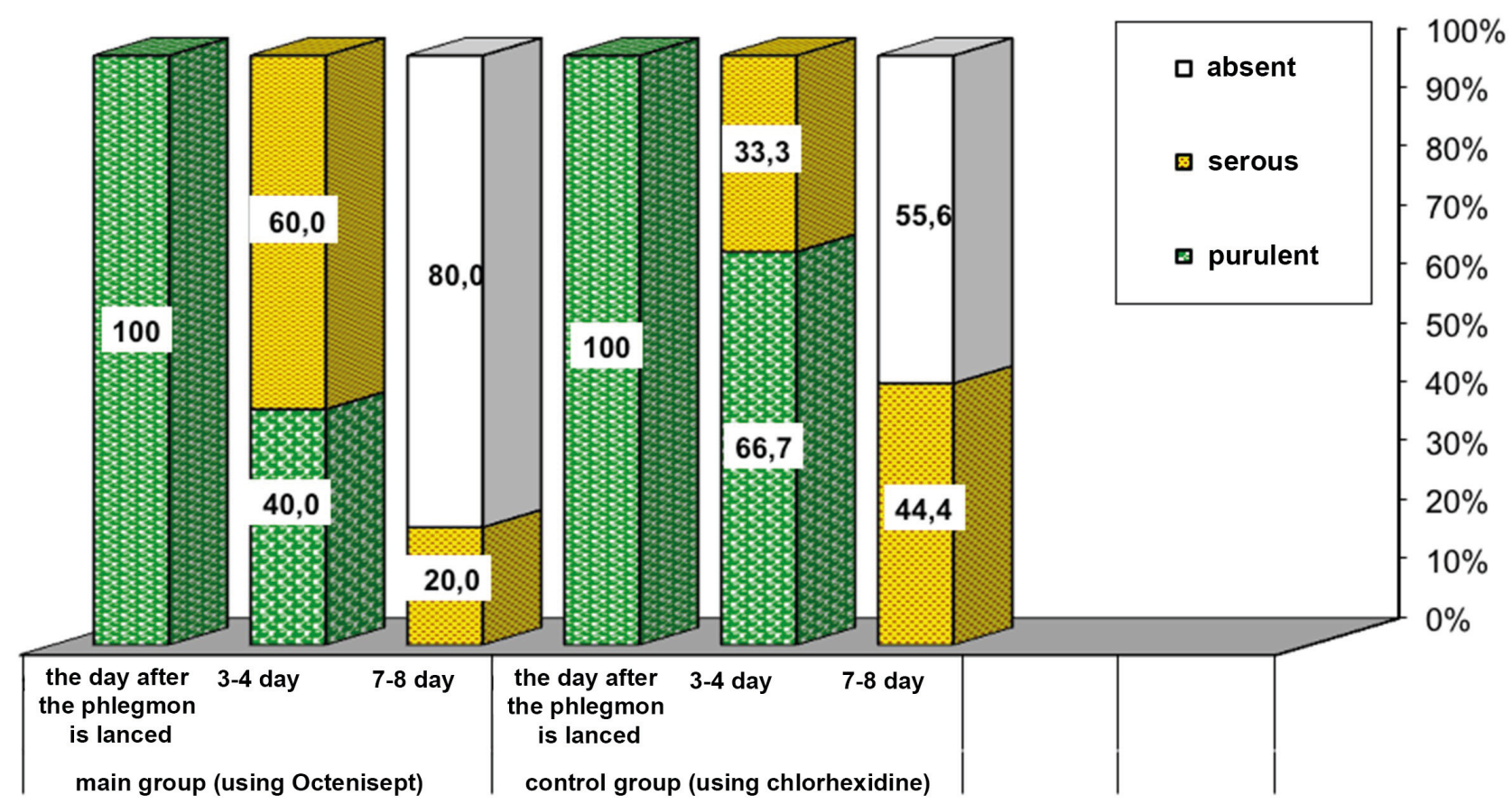

FIGURE 7. The presence of discharge from purulent wounds in patients with phlegmon of the maxillofacial area and neck in the dynamics of the treatment.

we did not reveal the appearance of similar granulations in the postoperative purulent wound in patients with phlegmon. On the 5-6th day of treatment with the drug "Octenisept", bright red granulations appeared in the postoperative purulent wound in patients with phlegmon in 14 patients (70 percent), and in the treatment with chlorhexidine - only 8 subjects (44.4\%). On 7-8th day of the local treatment with the drug "Octenisept", the appearance of bright red granulations in the postoperative purulent wound in patients with phlegmon was detected in all patients (100 percent), and in the treatment with chlorhexidine - only in 14 patients (77.8\%).

The terms of reducing the area of purulent wounds in patients with phlegmon of the maxillofacial area and neck in the dynamics of the treatment carried out (Fig 8) were determined. On the 3-4th day of the local treatment with the drug "Octenisept" (main group), a decrease in purulent wounds in patients with phlegmon was registered in 4 patients (20 percent), and in the same periods of treatment with chlorhexidine (control group) we had a decrease in purulent wounds revealed only in 1 patient $(5.6 \%)$. On the 5-6th day of the treatment with the drug "Octenisept", the reduction of purulent wounds in patients with phlegmon was observed in 16 patients (80 percent), and in the treatment with chlorhexidine - only in 9 patients (50 percent). On the 7-8th day of the local treatment, a decrease in the purulent wound was found in all the subjects, both in the main and control observation groups.

Changes in the severity of inflammatory infiltration of perimaxillary soft tissues in patients with phlegmon of the maxillofacial area and neck in the dynamics of treatment (Fig 10) were revealed. It was established that the next day after phlegmon dissection, severe inflammatory infiltration of perimaxillary soft tissues in patients with phlegmon was observed in 100 percent of cases both in the main observation group and in the control group. On the 3-4th day of the local treatment with the drug "Octenisept" (main group), severe inflammatory infiltration of the maxillary soft tissues was observed in 9 patients (45\%) and moderate - in 11 patients (55\%). For 3-4 days of treatment with chlorhexidine (control group), severe inflammatory infiltration of perimaxillary soft tissues was found in 14 patients $(77.8 \%)$, and moderate - in 4 patients 


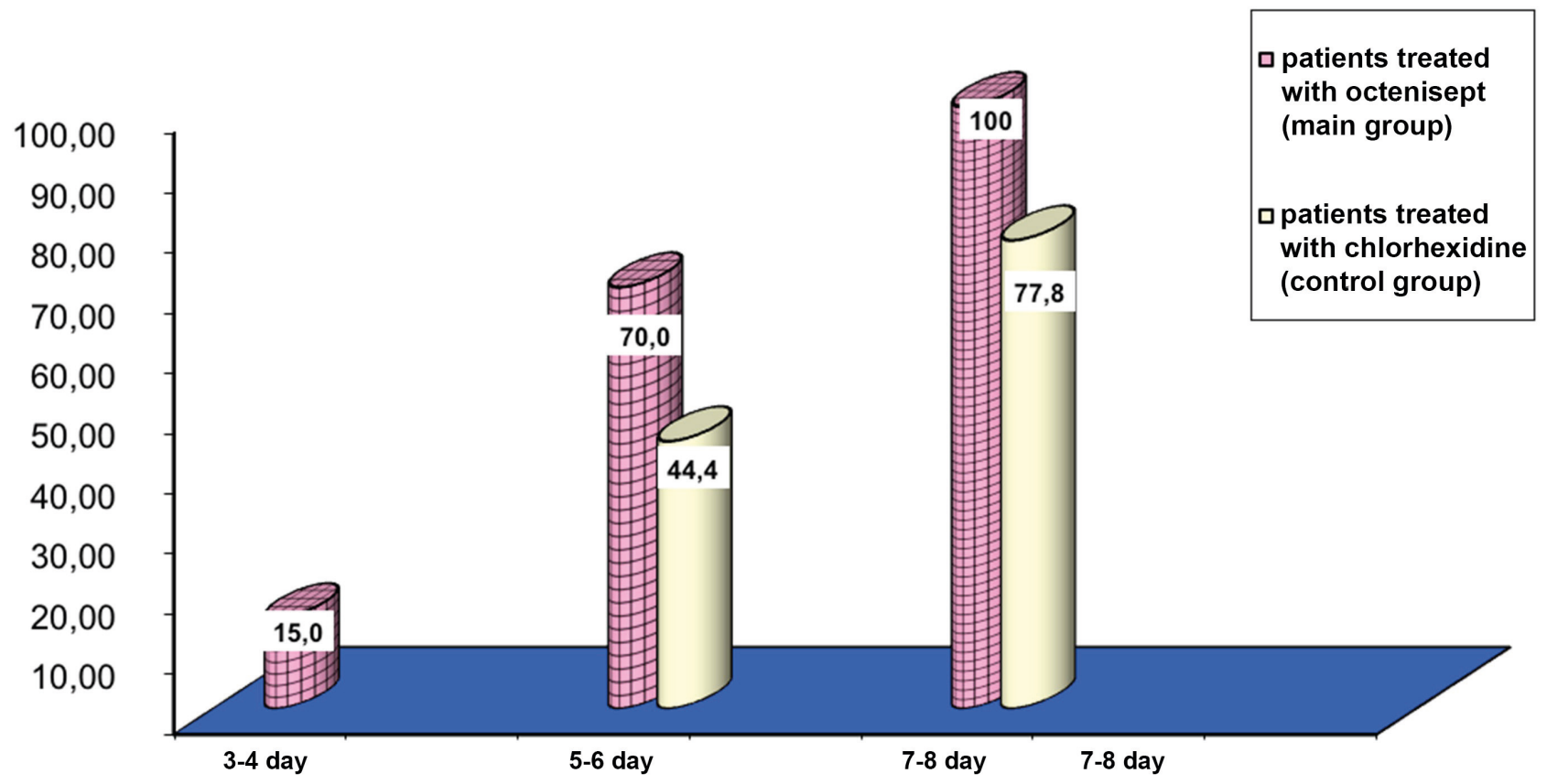

FIGURE 8. Dynamics of the Treatment: The timing of the appearance of granulations in the wound in patients with phlegmon of the maxillofacial and neck areas.



FIGURE 9. Terms of reducing the area of purulent wounds in patients with phlegmon of the maxillofacial area and neck in the dynamics of the treatment. 


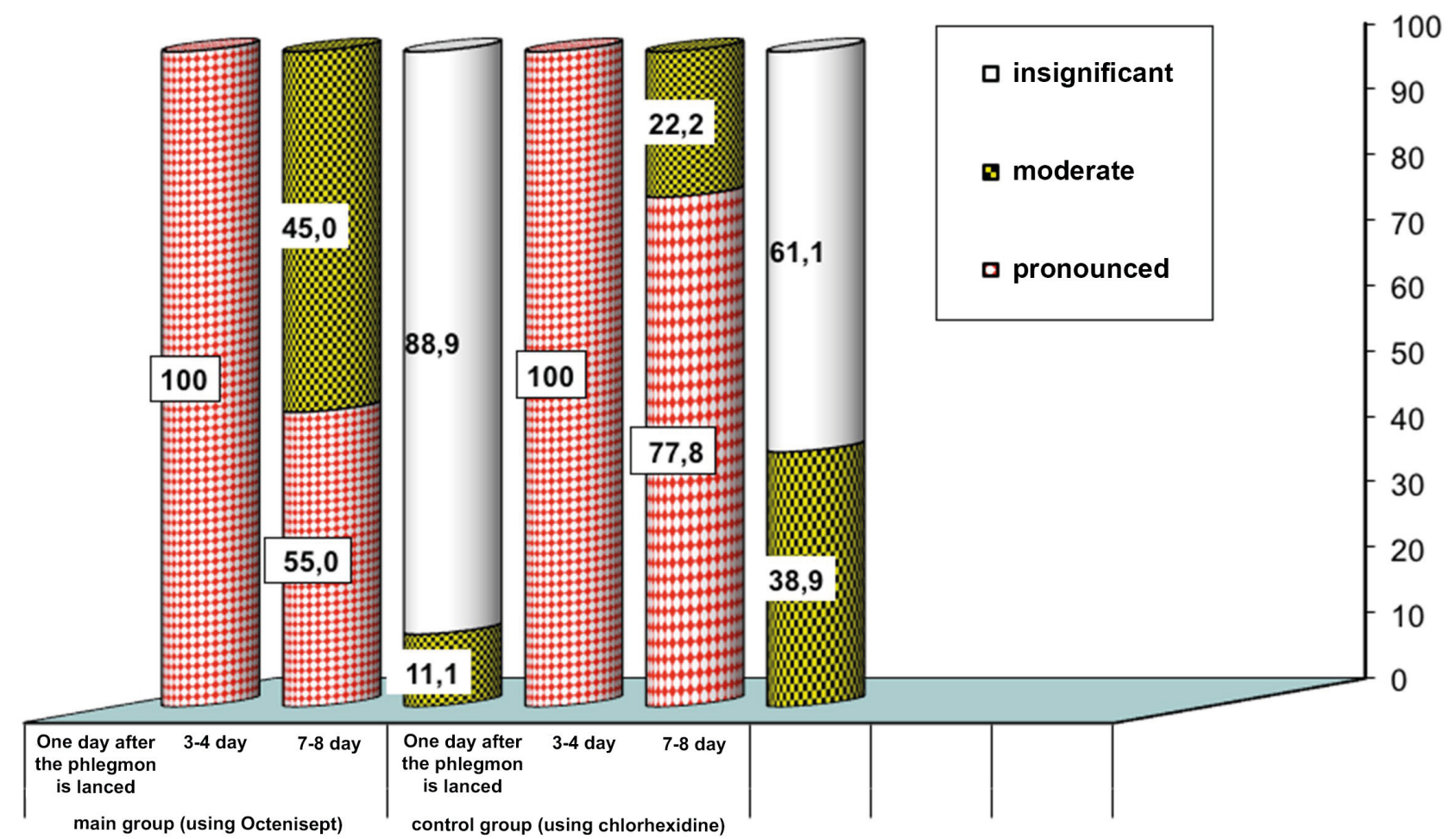

FIGURE 10. Changes in the severity of inflammatory infiltration of perimandibular soft tissues in patients with cellulitis of the maxillofacial area and neck in the dynamics of treatment.

(22.2\%). On the 7-8th day of local treatment with the drug "Octenisept", moderate inflammatory infiltration of perimaxillary soft tissues was observed in 2 patients $(11.1 \%)$, and in the rest inflammatory infiltration of perimandibular soft tissues insignificant (90\%). On the 7-8th day of the local treatment with chlorhexidine, moderate inflammatory infiltration of perimaxillary soft tissues was found in 7 surveyed (38.9 percent), and in the rest $(61.1 \%)$ - inflammatory infiltration of perimaxillary soft tissues was insignificant.

In the main observation group (with the treatment with the drug "Octenisept") in 18 patients (90 percent) with cellulitis we managed to impose early secondary sutures on the purulent wound with $100 \%$ effectiveness. In the control observation group (chlorhexidine treatment), we managed to impose early secondary sutures on a purulent wound in 9 patients with phlegmon (50\%) with an efficiency of 88.9 percent.

\section{CONCLUSIONS}

On the basis of the conducted examinations of patients with phlegmon of the maxillofacial area and neck, it was objectively proved that the antiseptic drug Octenisept used for the local treatment of purulent wounds has a pronounced antiseptic effect, which is much higher than that of traditional antiseptic agents (chlorhexidine). We did not find any side effects of the drug Octenisept.

In patients with phlegmon of the maxillofacial area and neck, the medication Octenisept can be recommended for the local treatment of purulent wounds in order to prevent the development of severe inflammatory complications.

\section{CONFLICT OF INTEREST}

The authors declare no conflict of interest.

\section{ROLE OF THE AUTHORS}

The authors are equally contributed to that paper.

\section{FUNDINGS}

No funding was received for this study. 


\section{ACKNOWLEDGMENTS}

None.

\section{REFERENCES}

1. Tymofieiev OO. Manual of maxillofacial and oral surgery [Russian]. 5th ed. Kyiv: Chervona Ruta-Turs; 2012.

2. Huang TT, Liu TC, Chen PR, Tseng FY, Yeh TH, Chen YS. Deep neck infection: analysis of 185 cases. Head Neck 2004;26:854-60. https://doi.org/10.1002/ hed.20014.

3. Yadav S, Verma A, Sachdeva A. Facial necrotizing fasciitis from an odontogenic infection. Oral Surg Oral Med Oral Pathol Oral Radiol 2012;113:e1-4. https://doi.org/10.1016/j.tripleo.2011.06.010.

4. Tymofieiev OO. Maxillofacial surgery [Ukrainian]. 2nd ed. Kyiv: Medytsyna; 2017.

5. Taub D, Yampolsky A, Diecidue R, Gold L. Controversies in the management of oral and maxillofacial infections. Oral Maxillofac Surg Clin North Am 2017;29:465-73. https://doi.org/10.1016/j. coms.2017.06.004.

6. Tymofieiev OO. Maxillofacial surgery [Russian]. 2nd ed. Kyiv: Medytsyna; 2015.

7. Hülsemann W, Habenicht R. Severe side effects after Octenisept irrigation of penetrating wounds in children [German]. Handchir Mikrochir Plast Chir 2009;41:277-82. https://doi. org/10.1055/s-0029-1238282.

8. Gore MR. Odontogenic necrotizing fasciitis: a systematic review of the literature. BMC Ear Nose Throat Disord 2018;18:14. https://doi.org/10.1186/ s12901-018-0059-y.

9. McQuinn M, Horswell BB. First case of cutaneous orbital abscess caused by Gemella: a case report and review of the literature. J Oral Maxillofac Surg 2019;S0278-2391(19):30124-7. https://doi. org/10.1016/j.joms.2019.01.049.

10. Bulgurcu S, Arslan IB, Demirhan E, Kozcu SH, Cukurova I. Neck abscess: 79 cases. North Clin Istanb 2015;2:222-6. https://doi.org/10.14744/ nci.2015.50023.

11. Abramowicz S, Rampa S, Allareddy V, Lee MK. The burden of facial cellulitis leading to inpatient hospitalization. J Oral Maxillofac Surg 2017;75:165667. https://doi.org/10.1016/j.joms.2017.01.032.

12. Shaariyah MM, Marina MB, Mohd Razif MY, Mazita A, Primuharsa Putra SH. Necrotizing fasciitis of the head and neck: surgical outcomes in three cases.
Malays J Med Sci 2010;17:51-5.

13. Park E, Hirsch EM, Steinberg JP, Olsson AB. Ascending necrotizing fasciitis of the face following odontogenic infection. J Craniofac Surg 2012;23:e211-4. https:// doi.org/10.1097/SCS.0b013e31824de3e7.

14. Gujrathi AB, Ambulgekar V, Kathait P. Deep neck space infection - a retrospective study of 270 cases at tertiary care center. World J Otorhinolaryngol Head Neck Surg 2016;2:208-13. https://doi.org/10.1016/j. wjorl.2016.11.003.

15. Rana RS, Moonis G. Head and neck infection and inflammation. Radiol Clin North Am 2011;49:165-82. https://doi.org/10.1016/j.rcl.2010.07.013.

16. Yang W, Hu L, Wang Z, Nie G, Li X, Lin D, Luo J, Qin $\mathrm{H}, \mathrm{Wu}$ J, Wen W, Lei W. Deep neck infection: a review of 130 cases in Southern China. Medicine (Baltimore) 2015;94:e994. https://doi.org/10.1097/ MD.0000000000000994.

17. Brito TP, Hazboun IM, Fernandes FL, Bento LR, Zappelini CEM, Chone CT, Crespo AN. Deep neck abscesses: study of 101 cases. Braz J Otorhinolaryngol 2017;83:341-8. https://doi. org/10.1016/j.bjorl.2016.04.004.

18. Song CW, Yoon HJ, Jung DW, Lee SH. Cervical Necrotizing Fasciitis Caused by Dental Infection. Maxillofac Plast Reconstr Surg 2014;36:67-72. https:// doi.org/10.14402/jkamprs.2014.36.2.67.

19. Cutilli T, Cargini P, Placidi D, Corbacelli A. Necrotizing fasciitis of the maxillofacial region caused by dental infection. A case report and review. Minerva Stomatol 2007;56:469-76.

20. Chalifoux JR, Vachha B, Moonis G. Imaging of Head and Neck Infections: Diagnostic Considerations, Potential Mimics, and Clinical Management. Semin Roentgenol 2017;52:10-6. https://doi.org/10.1053/j. ro.2016.07.004.

21. Qiu Y, Li Y, Gao B, Li J, Pan L, Ye Z, Lin Y, Lin L. Therapeutic efficacy of vacuum sealing drainageassisted irrigation in patients with severe multiplespace infections in the oral, maxillofacial, and cervical regions. J Craniomaxillofac Surg 2019;47:837-41. https://doi.org/10.1016/j.jcms.2019.01.031.

22. Heim N, Faron A, Wiedemeyer V, Reich R, Martini M. Microbiology and antibiotic sensitivity of head and neck space infections of odontogenic origin. Differences in inpatient and outpatient management. J Craniomaxillofac Surg 2017;45:1731-5. https://doi. org/10.1016/j.jcms.2017.07.013.

23. Opitz D, Camerer C, Camerer DM, Raguse JD, Menneking H, Hoffmeister B, Adolphs N. Incidence and management of severe odontogenic infections - a retrospective analysis from 2004 to 2011. J 
Craniomaxillofac Surg 2015;43:285-9. https://doi. org/10.1016/j.jcms.2014.12.002.

24. Zemplenyi K, Lopez B, Sardesai M, Dillon JK. Can progression of odontogenic infections to cervical necrotizing soft tissue infections be predicted? Int J Oral Maxillofac Surg 2017;46:181-8. https://doi. org/10.1016/j.ijom.2016.09.016.

25. Hussein QA, Anaya DA. Necrotizing soft tissue infections. Crit Care Clin 2013;29:795-806. https:// doi.org/10.1016/j.ccc.2013.06.001.

26. Kent S, Hennedige A, McDonald C, Henry A, Dawoud B, Kulkarni R, Logan G, Gilbert K, Exely R, Basyuni S, Kyzas P, Morrison R, McCaul J. Systematic review of the role of corticosteroids in cervicofacial infections. Br J Oral Maxillofac Surg 2019;57:196-206. https:// doi.org/10.1016/j.bjoms.2019.01.010.

27. McDonald C, Hennedige A, Henry A, Dawoud B, Kulkarni R, Gilbert K, Kyzas P, Morrison R,
McCaul JA; Maxillofacial Trainee Collaborative. Management of cervicofacial infections: a survey of current practice in maxillofacial units in the UK. $\mathrm{Br}$ J Oral Maxillofac Surg 2017;55:940-5. https://doi. org/10.1016/j.bjoms.2017.09.002.

28. Roy S, Sainuddin S, Clark S. Odontogenic infections: a national survey to assess confidence of the OMFS "first on-call". Br J Oral Maxillofac Surg 2016;54:1102-5. https://doi.org/10.1016/j. bjoms.2016.08.001.

29. Terzic A, Scolozzi P. Deep neck space abscesses of dental origin: the impact of Streptococcus group Milleri. Eur Arch Otorhinolaryngol 2014;271:2771-4. https://doi.org/10.1007/s00405-013-2822-4.

30. Wang LF, Kuo WR, Tsai SM, Huang KJ. Characterizations of life-threatening deep cervical space infections: a review of one hundred ninety-six cases. Am J Otolaryngol 2003;24:111-7. 